\title{
CARDIOVASCULAR DISEASE IN A RANDOM SAMPLE OF ELDERLY PEOPLE
}

\author{
BY \\ H. DROLLER, AND JOHN PEMBERTON \\ From the Department of Social and Industrial Medicine, The University of Sheffield \\ Received November 13, 1952
}

The observations that follow give some indication of the prevalence of the commoner cardiovascular diseases, including cerebrovascular accidents and the disability resulting therefrom, in a random sample of 476 elderly people living at home in Sheffield. They are based on full clinical examinations which were carried out in the subjects' homes.

The importance of cardiovascular disease in the elderly needs no emphasis. It accounted for 42 per cent of all deaths of men over pensionable age (65+) and the same percentage of all deaths of women over pensionable age $(60+)$ in England and Wales in 1949 (Int. List Nos. 90-103). If deaths from intracranial lesions of vascular origin (Int. List No. 83) are added, the figures become 54 and 58 per cent.

Of the 476 subjects, 192 were men and 284 women. Eighty per cent of the men and 47 per cent of the women were over 70 years of age.

\section{Derivation OF SAMPLE}

In 1948, a social survey had been carried out by the Council of Social Service on a $1: 30$ sample of all Sheffield people of pensionable age, (Greenlees and Adams, 1950). The sample had been selected by a random procedure from the food office register. The group of elderly people used in the medical survey was derived from this sample and included all those living alone or living alone with spouse who could be traced and agreed to be examined. Those living alone or alone with spouse were chosen to facilitate a dietary survey which was carried out at the same time. Of 736 possible subjects, 260 were not available when the medical survey came to be done. Sixty-four had died. Thirty-six were no longer living alone or alone with spouse, 18 had left Sheffield or could not be traced, and in 142 cases, consent for the examination was withheld. As two years had elapsed between the two surveys, the youngest women in the medical survey were 62 and youngest men 67 . The sample included all social classes and we believe was reasonably representative of elderly people living independently at home. There was, however, a slightly higher proportion of women and of representatives of the higher income groups amongst the refusals. Ninety-four per cent of the medical examinations were carried out by one physician (H.D.).

\section{Previous Surveys}

Sheldon (1948) appears to have been the only other investigator to have reported on a medical survey of old people in their homes. He interviewed 477 old people but did not carry out an examination of the cardiovascular system or measure the blood pressure. Gavey (1949) described the cardiovascular conditions found in 360 elderly people attending hospital for ophthalmic and other conditions including cardiac conditions. Neither of these surveys is strictly comparable with ours, the former, because similar investigations were not carried out, and the latter because the subjects were largely selected on account of sickness. Where possible, however, in the absence of more comparable material, we have compared the findings of these authors with our own.

In a health survey which includes those who are not ill as well as those who are, it is sometimes difficult to know how to classify people in whom morbid conditions are found that are not causing symptoms. This problem is particularly prominent when considering cardiovascular disease in 
the elderly, as few people over 65 do not show some evidence of degeneration of the heart or blood vesids. Arteriosclerosis and hypertension, often with no symptoms, are so common that they have been excluded from consideration here except for the few cases of heart failure in which hypertension appeared to be an important cause. The data on the blood pressures have been published elsewhere (Droller et. al., 1952).

In trying to assess the importance of cardiovascular disease in this group, it appeared to be preferable in the first place to concentrate on those who were to some extent disabled by these conditions. What follows, therefore, is primarily concerned with the 87 subjects (18 per cent of the whole sample) whose activity was limited by cardiovascular disease. Some indication has also been given, where possible, of the numbers who had signs of these conditions with few or no symptoms and whose activity was apparently unaffected.

\section{AnAlysis of Function AND EfFeCt of AGE}

The functional analysis was based mainly on the subject's own assessment of his activity. According to his description, he was placed in one of four categories.

1. Outside unlimited activity

2. Outside limited activity

3. Confined to the house

4. Confined to bed.

Of the 87 whose activity was limited, only 2 were bedridden; both were women suffering from hemiplegia after a cerebrovascular accident. Four men and 16 women were confined to the house, and the remainder were able to undertake a limited amount of out of door activity such as pottering about the yard or calling on neighbours.

There were too few cases in our series to assess the effect of age on the incidence of the separate conditions, but when both sexes and all cardiovascular conditions were combined, there was an increase in the incidence of disablement with age from 6.8 per cent at age 60-64 to 30.8 per cent age 75 and over. The overall incidence was slightly higher in the women, 20 per cent, than in the men, 16 per cent.

\section{Diagnosis and Degree of Disablement by Heart Disease}

The diagnosis of those whose activity was judged to be limited by cardiovascular disease and the degrees of limitation are shown in the Table.

Angina of effort. Angina of effort was the commonest condition found. Thirty-one subjects (6.5 per cent of the whole sample) suffered from angina to an extent sufficient to limit activity but a further $99(20.5$ per cent) complained of the symptom to a lesser degree. The condition was equally frequent in men and women. It was remarkable how many of those with angina refused to allow it seriously to interfere with their activities. For example, 13.5 per cent of the men with angina were still in whole-time employment. This figure may be compared with the 21 per cent of all the 192 men still in employment.

Pulmonary heart failure. Thirty-two (7\%) of the total sample were disabled by chronic bronchitis, emphysema, and bronchospasm, and of these, four men and five women ( 2 per cent of the whole sample) had developed chronic cor pulmonale.

Chronic bronchitis and hypertension were not infrequently associated and it was difficult in some cases to decide in cases of early heart failure in which both were present, whether the cardiac failure was of pulmonary or hypertensive origin.

The records were examined to see whether the incidence of hypertension was abnormally high in those with chronic bronchitis. Altogether 189 of the 476 subjects suffered from some degree of chronic bronchitis, usually accompanied by emphysema and occasional wheezing. Of the 189 with bronchitis, 40 per cent had systolic blood pressures of 180 or more while of the 262 without 
bronchitis, 48 per cent had blood pressures of 180 or more. This difference was shown by the $\mathrm{X}^{2}$ test to be not statistically significant. Neither was bronchitis any commoner in those with diastolic pressures of $100 \mathrm{~mm}$./ $\mathrm{Hg}$ or more, than in those with pressures under this figure. There does not therefore appear to be any significant association between chronic bronchitis and high blood pressure in the elderly. The two conditions are both so common that they inevitably often occur together.

Hypertension and heart failure. Nineteen per cent of the men and 29 per cent of the women had a systolic blood pressure of $190 \mathrm{~mm}$./ $\mathrm{Hg}$ or more and 28 per cent of men and 48 per cent of women had a diastolic pressure of $100 \mathrm{~mm} . / \mathrm{Hg}$ or more. In other words, on these criteria, approximately one-third of the subjects had hypertension. A good many of these also had various combinations of the following symptoms and signs: angina of effort, dyspnœa on slight exertion, chronic cough and wheezing, emphysema, and nocturnal dyspnœa. So much was this so, that we found it difficult to diagnose " hypertensive heart disease" as an entity with confidence. In nearly all the cases with high blood pressure as defined above in which there were signs of heart failure, other conditions such as coronary artery disease or chronic bronchitis with emphysema and bronchospasm were present which could have been responsible for the heart failure. Finally, and with some doubt, we allotted 9 cases ( 3 men and 6 women) to the group " hypertensive heart failure."

The examinations tended to confirm the view that hypertension in those over 65 is usually benign. In a special study of the blood pressure in this group of elderly people (op. cit.) we showed that high sphygmomanometer readings showed no. statistical correlation with angina pectoris, enlargement of the heart judged radiologically, or the subject's well-being and activity.

Cerebrovascular accidents. In many cases, it is impossible to nurse the elderly patient who has

\section{INCIDENCE OF CARDIOVASCULAR DISEASE CAUSING LIMITATION OF ACTIVITY IN 476} ELDERLY PEOPLE

\begin{tabular}{|c|c|c|c|c|c|c|c|c|}
\hline & \multicolumn{3}{|c|}{192 Men } & \multicolumn{3}{|c|}{284 Women } & \multirow{2}{*}{$\mid$\begin{tabular}{|c|} 
All 476 \\
$\begin{array}{c}\text { Some } \\
\text { limitation }\end{array}$
\end{tabular}} & \multirow{2}{*}{$\begin{array}{l}\text { Percentage } \\
\text { of whole } \\
\text { sample }\end{array}$} \\
\hline & Bed-ridden 1 & House fast & $\begin{array}{l}\text { Limited } \\
\text { outdoor }\end{array}$ & Bed-ridden & House fast & $\begin{array}{l}\text { Limited } \\
\text { outdoor }\end{array}$ & & \\
\hline Angina of effort .. & & 1 & 11 & & 3 & 16 & 31 & $6 \cdot 5$ \\
\hline $\begin{array}{l}\text { Pulmonary } \\
\text { heart failure } \quad . .\end{array}$ & & 1 & 3 & & 3 & 2 & 9 & $2 \cdot 0$ \\
\hline 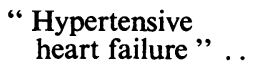 & & & 3 & & & 6 & 9 & $2 \cdot 0$ \\
\hline $\begin{array}{l}\text { Cerebro-vascular } \\
\text { accident. . }\end{array}$ & & 1 & 1 & 2 & 5 & & 9 & $2 \cdot 0$ \\
\hline $\begin{array}{c}\text { Rheumatic heart } \\
\text { disease } \ldots\end{array}$ & & & 1 & & 1 & 4 & 6 & $1 \cdot 3$ \\
\hline $\begin{array}{l}\text { Degenerative } \\
\quad \text { aortic disease } \ldots\end{array}$ & & 1 & 1 & & 1 & 3 & 6 & $1 \cdot 3$ \\
\hline $\begin{array}{l}\text { Peripheral } \\
\text { vascular disease }\end{array}$ & & & 3 & & & & 3 & $0 \cdot 6$ \\
\hline $\begin{array}{cc}\text { Syphilitic aortic } & \\
\text { disease } & . .\end{array}$ & & & 1 & & & 1 & 2 & 0.4 \\
\hline Miscellaneous & & & 3 & & 3 & 6 & 12 & $2 \cdot 5$ \\
\hline TOTAL .. & & 4 & 27 & 2 & 16 & 38 & 87 & $18 \cdot 0$ \\
\hline
\end{tabular}


had a cerebrovascular accident at home, and so he or she is admitted to hospital. For this reason, it is not a very common finding in old people at home. Where an elderly person who has had a stroke is kept at home, either voluntarily or because of difficulty in securing admission to hospital, the burden on the relatives may be very heavy.

Altogether, there were 7 women and 2 men ( 2 per cent of the sample) whose activity was limited by cerebrovascular accidents. Sheldon found 4 per cent in his series, but he included patients who had recovered from a stroke.

Rheumatic mitral disease. One man and 5 women were to some extent disabled by rheumatic heart disease. That is, an incidence of 1.3 per cent. Several of these cases had other possible causes of disablement, including angina, in addition to the rheumatic lesion.

Angina is described as a rare symptom in mitral stenosis. White (1944) states that it is " almost always due to an incidental complication of coronary heart disease." The proportion of subjects with mitral stenosis who also had angina was similar to the proportion who had angina in the whole sample. It would seem likely that the angina in these subjects was due to concurrent coronary artery disease, rather than to the rheumatic heart disease.

Degenerative aortic valve disease. Two men and 4 women had degenerative aortic valve disease causing reduced activity and other symptoms. In addition, there were 2 men and 1 woman with this condition who had no limitation of activity. The total incidence therefore was 2 per cent. Gavey found an incidence of 1.7 per cent.

Of the 9 cases, 4 had both systolic and diastolic aortic murmurs, 4 had aortic systolic murmurs only and $1 \mathrm{had}$ an aortic diastolic murmur only. The subjects with regurgitation were more disabled than those in whom stenosis was the prominent feature. Two of the 5 with regurgitation were confined to the house, but none of the 4 with stenosis.

Peripheral vascular system. There were no cases of senile peripheral gangrene. Intermittent claudication was the most disabling variety of peripheral vascular disease that was encountered. There were 20 men and 9 women who had this symptom in some degree, but only in 3 , all men, was it bad enough to limit activity.

Disabling intermittent claudication in the elderly would appear to be practically confined to men and its incidence in them to be about 1.5 per cent. Sheldon and Gavey both found a similar incidence.

Syphilitic aortic disease. There were only two examples of syphilitic aortic disease discoverd in our series, a woman of 65 and a man of 68 . In both, the blood W.R. was positive and in both their activity was limited by the disease, though in the case of the man, the limitation was not severe.

Syphilitic aortic disease is not common now. Even in the elderly, the incidence appears to be less than 0.5 per cent, and because of recent advances in treatment, it should eventually become rare. Gavey found no cases in his series.

Congenital heart disease. No cases of congenital heart disease were discovered. Gavey found one case out of 360 patients. It appears to be very rare for persons with congenital heart disease to survive the age of 60 .

Auricular fibrillation and congestive cardiac failure. Auricular fibrillation was diagnosed on the basis of the clinical examination alone as no electrocardiographic examinations were made. The incidence, therefore, is possibly an underestimate. Three men $(1.5 \%)$ and 12 women $(4 \%)$ had this irregularity and the underlying cardiac conditions were varied. It was usually a sign of serious cardiac disease. Eleven of the 15 subjects whose hearts were fibrillating were limited in their activities and 6 had developed congestive cardiac failure. It may be noted that of the whole sample, only 3 men and 11 women $(3 \%)$ were found to have congestive cardiac failure.

\section{Heart Disease Secondary to Disease in Other Organs}

Renal heart failure. No cases of heart disease that could be attributed to renal disease were found. This excludes those subjects with various degrees of albuminuria with or without hypertension in which renal atherosclerosis was probably present. 
Thyrotoxic heart disease. There were 5 subjects, all women, who had thyroid enlargements and evidence of heart disease. In only one did it appear that the heart condition was due to toxic changes in the thyroid.

Myxadema and heart disease. There were 3 cases of myxœdema (1\%), all women. All had hypertension.

Osteitis deformans and cardiovascular disease. The findings in the small group of proved cases of Paget's disease in this series, 7 men and 2 women, suggested that osteitis deformans predisposes to, or aggravates existing cardiovascular disease (Edholm, Howarth, and McMichael, 1945). Only those cases with at least two of three criteria of Paget's disease-clinical evidence, radiological evidence, and serum alkaline phosphatase of 35 units or above-were included. Of the 7 men, all had marked clinical arteriosclerosis, 5 had low systolic and diastolic blood pressures, 3 had early congestive cardiac failure, and 2 degenerative aortic incompetence; 4 of the 5 whose chests were radiographed had enlarged hearts. These findings were all much commoner in the cases of Paget's disease than they were in the whole sample. There were too few cases amongst the women to justify comment.

Cardiovascular disease of mixed or indeterminate atiology. In a good many of the cases in this series, more than one pathological process was contributing to the disability. In some, pulmonary disease was co-existent with cardiac disease, in others, more than one type of cardiovascular disease was present, for example, coronary artery disease and mitral stenosis. Where it was found to be impossible to classify a case under a single cardiac heading, it was classed as mixed or indeterminate.

In old age, the heart may fail at last, not from one but from several causes. It may then be very difficult, as experienced general practitioners know, to make a more precise diagnosis than " heart failure." As this term is unacceptable for the purposes of registration, such cases are often diagnosed as myocarditis or myocardial degeneration and go to make up the huge total of deaths ascribed to these causes in England and Wales; 85,134 in 1949, or 49 per cent of all circulatory deaths.

\section{Summary AND CONCLUSIONS}

A random sample of 476 people over pensionable age living at home, alone or alone with their husband or wife, were examined clinically. The incidence of the various cardiovascular disorders is given and the amount of disability caused by them is described. In 18 per cent of the sample, there was some limitation of activity due to this group of diseases.

Angina of effort was the commonest disorder found, followed by pulmonary heart disease, hypertensive heart failure, and cerebrovascular accidents in equal numbers. Then came rheumatic heart disease, degenerative aortic disease, peripheral vascular disease, and syphilitic aortitis. A miscellaneous group included some cases of heart disease secondary to other diseases such as osteitis deformans or thyrotoxicosis and a group of cases in which there appeared to be more than one cause of heart failure, for example, coronary artery disease and mitral stenosis. A surprisingly large number of the subjects who had evidence of cardiovascular disease were not apparently limited in their activity.

The general picture of cardiovascular disease in this group of elderly people which emerged was, as would be expected, one in which conditions resulting from arterial degeneration predominated. Many had evidence of a gradual cutting off of the cardiac circulation with the consequent cardiac pain and limitation of activity. In a smaller number, interruption of the circulation had occurred in more distal parts such as the brain causing paresis and mental changes, or the legs causing intermittent claudication. Syphilitic heart disease now appears to be rare in the elderly, but rheumatic heart disease is not very uncommon if the incidence of 1.3 per cent found in this series is representative. Chronic cor pulmonale accounted for 2 per cent of the cases and with the more effective treatment of acute exacerbations of chronic respiratory disease in the elderly which is now possible, this variety of heart failure may well become more common in the future. There was no significant association between chronic bronchitis and hypertension. 
The most striking finding was not the number who were disabled but the much greater number who, in spite of having multiple signs of cardiovascular disease, were living full and active lives. In the whole sample of 476 , there were only 2 who were bedridden and 20 who were confined to their homes because of cardiovascular disease. It is of course true that a good many elderly people with serious cardiovascular disease are admitted to hospital and that the small number of bedridden old people in this series does not give a true indication of the total number of serious cases of cardiovascular disease in the elderly population. However, a rough calculation based on the number of hospital beds in Sheffield normally occupied by the elderly, and on the assumption that half are occupied by patients with cardiovascular disease, indicates that only about 8 additional bedridden cases would have to be added to this sample to make it representative.

We wish to thank Professor W. Hobson and Miss C. Roseman for their helpful suggestions in the preparation of this paper.

\section{REFERENCES}

Droller, H., Pemberton, J., Roseman, C., and Grout, J. L. A. (1952). Brit. med. J., 2, 968.

Edholm, O. G., Howarth, S., and McMichael, J. (1945). J. Clin. Sc., 5, 249.

Gavey, C. J. (1949). Lancet, $2,725$.

Greenlees, A., and Adams, J. (1950). Old People in Sheffield. Sheffield.

Sheldon, J. H. (1948). The Social Medicine of Old Age. London.

White, P. D. (1944). Heart Disease. New York. 